\title{
SUBDOSES DE GLYPHOSATE NO DESENVOLVIMENTO DE ESPÉCIES ARBÓREAS NATIVAS
}

\author{
GLYPHOSATE REDUCED RATES ON THE DEVELOPMENT OF NATIVE TREE \\ SPECIES
}

\section{Maria Renata Rocha PEREIRA ; Guilherme Sasso F. de SOUZA² ${ }^{2}$ Edson Diniz Fonseca ${ }^{3}$; Dagoberto MARTINS ${ }^{4}$}

1. Engenheira Florestal, Professora, Doutora, Faculdade de Tecnologia de Capão Bonito - FATEC, Capão Bonito, SP, Brasil. mariarenatarp@ hotmail.com; 2. Engenheiro agrônomo, Doutorando, Departamento de Produção Vegetal - FCA, Universidade Estadual Paulista - UNESP, Botucatu, SP, Brasil; 3. Tecnólogo em Silvicultura, Pesquisador Suzano Papel e Celulose, Itapetininga, SP, Brasil; 4. Engenheiro agrônomo, Professor Livre-Docente, Departamento de Produção Vegetal, Faculdade de Ciências Agrárias e Veterinária FCAV - UNESP, Jaboticabal, SP, Brasil.

RESUMO: A recuperação de áreas degradadas tem o objetivo de fornecer ao ambiente degradado condições favoráveis a reestruturação em um ambiente que não tem condições de se regenerar por si só, sendo o plantio de mudas arbóreas uma forma efetiva de ampliar este processo. Entretanto as espécies arbóreas nativas têm ritmo de crescimento lento, o que aumenta o tempo da produção da muda, como também diminui a competitividade destas com as plantas daninhas em áreas de implantação de florestas. O objetivo deste estudo foi avaliar os efeitos da aplicação de subdoses de glyphosate no desenvolvimento de mudas de Psidium cattleyanum (araçá-amarelo), Citharexylum myrianthum (pau-viola) e Cedrela odorata (cedrinho), através da análise de seus parâmetros morfofisiológicos. O experimento foi instalado e conduzido em casa de vegetação, e as unidades experimentais foram constituídas de uma planta, conduzida em vasos com capacidade para 2,5L, dispostos inteiramente ao acaso, arranjados em uma esquema fatorial (doses x espécies), com seis repetições. Os

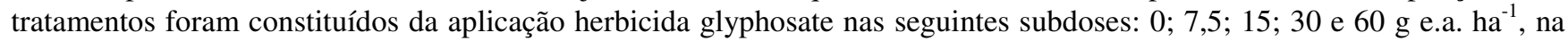
formulação comercial Scout@. A aplicação nas mudas foi realizada aos 120 dias após germinação. Foram realizadas avaliações dos efeitos dos tratamentos químicos (fitointoxicação) sobre as plantas aos 7, 14 e 21 dias após aplicação, e após 90 dias foram avaliados a sobrevivência das plantas, condutância estomática, altura, diâmetro do caule e massa seca de parte aérea. As diferentes doses do herbicida não provocaram intoxicação às plantas. Já a dose de $30 \mathrm{e} 60 \mathrm{~g}$ e.a. ha ${ }^{-1}$ proporcionou maiores incrementos em altura e diâmetro, bem como maiores massas secas em plantas de pau-viola e araçá-amarelo, respectivamente.

PALAVRAS-CHAVE: Psidium cattleyanum. Citharexylum myrianthum. Cedrela odorata. Herbicida.

\section{INTRODUÇÃO}

A constante expansão agrícola, aliada a uma visão de abundância dos recursos naturais, força, continuamente, a conversão de mais áreas para a agricultura, ampliando o processo de degradação ambiental (RIBEIRO et al., 2005).

De acordo com Fernandes et al., (2000) as áreas de nascentes de água e as matas ciliares têm sofrido um processo contínuo de devastação, com grandes consequências ecológicas e ambientais. Por esta razão, a sociedade tem-se mobilizado no sentido de preservar as áreas remanescentes e replantar com espécies nativas os locais degradados pela mineração, construção civil, construção de reservatórios das usinas hidrelétricas como também pela utilização do solo para fins agrícolas.

Dentre os métodos de regeneração artificial utilizados para recuperação de áreas degradas, destaca-se o plantio de mudas, que, por ser rápido e eficiente na proteção do solo contra a erosão, torna-se o mais empregado em plantios florestais com espécies nativas. A principal maneira de se realizar a recomposição florestal é usando mudas de espécies nativas da região, o que envolve a identificação das espécies, métodos de monitoramento do processo de produção das mudas como o armazenamento das sementes, a semeadura, a germinação e o desenvolvimento das plantas, sendo todos estes fatores variáveis de uma espécie para a outra (FERREIRA et al., 2009).

$\mathrm{Na}$ implantação dos plantios florestais a presença das plantas daninhas nos primeiros meses é considerada um dos maiores problemas enquanto ainda não se tem um dossel fechado, sendo necessário um controle efetivo destas para evitar a matocompetição (PITELLI; MARCHI, 1991). De acordo com Toledo et al. (2001), a partir de 4 plantas por $\mathrm{m}^{-2}, \quad \mathrm{o} \quad$ capim-braquiária interfere significativamente no crescimento inicial de mudas de eucalipto, que é considerada uma espécie arbórea de rápido crescimento, reduzindo em média $28 \%$ o diâmetro do caule e $18 \%$ na altura das plantas, 90 dias após o transplantio.

Estudos recentes demonstram que a deriva, ou seja, o contato da planta com uma pequena 
quantidade do herbicida glyphosate, que é um dos poucos herbicidas registrados para as culturas florestais no Brasil (RODRIGUES; ALMEIDA, 2005), proporciona um maior desenvolvimento das plantas de E. grandis, conforme também demonstrado por Pereira et al. (2010) que, com a aplicação de $30 \mathrm{~g}$ ha $^{-1}$ deste herbicida em plantas 30 dias após transplantio, observou uma diminuição da resistência estomática e consequente aumento da transpiração gerando uma redução na temperatura das folhas, sugerindo um aumento no crescimento.

Diante do exposto pode-se verificar que os estudos são direcionados para a cultura do eucalipto por ser uma espécie de grande valor econômico, mas que não são utilizadas na recuperação de áreas degradadas. Em contraste, estudos sobre as espécies florestais nativas, de uma maneira geral são incipientes e relacionam-se principalmente às características botânicas e dendrológicas. Pouco se sabe sobre as características silviculturais, o padrão de crescimento e as exigências nutricionais de muitas espécies florestais (GARRIDO, 1981). Sabe-se que estas espécies arbóreas têm ritmo de crescimento lento, o que aumenta o tempo da produção da muda, como também diminui a competitividade destas com as plantas daninhas em áreas de implantação florestal.

Assim, a aplicação de subdoses de glyphosate pode ser um recurso viável para aumentar o desenvolvimento das mudas de espécies nativas, tanto na fase de produção das mudas quanto no crescimento no campo, sendo uma linha de pesquisa que ainda está carente de informações, devido às limitações de conhecimento na utilização deste herbicida como fitoregulador.

Entre as espécies utilizados na recomposição de matas ciliares se encontram Psidium cattleyanum Sabine, Citharexylum myrianthum Cham. e Cedrela odorata L..

Psidium cattleyanum (araçá-amarelo), pertencente à família Myrtaceae, é uma espécie arbórea característica da mata pluvial atlântica, com altura de 3-6 metros e tronco de $15-25 \mathrm{~cm}$ de diâmetro. (IBF, 2013). Característica da zona da mata pluvial da encosta atlântica, ocorrendo em terrenos rochosos úmidos e compactos, à margem ou no interior de matas semidevastadas e capoeirões, podendo ocorrer à beira de vertentes e até em banhados (REITZ; KLEIN, 1977).

A espécie Citharexylum myrianthu, também conhecida como pau-viola, pertencente à família Verbenaceae, pode atingir de 15 e 20 metros de altura. Possui tronco reto e, às vezes, levemente curvo, tendo medidas que variam de 40 e 60 centímetros de diâmetro. Também ocorrem da Bahia até o Rio Grande do Sul, na floresta pluvial atlântica e matas de galeria (LORENZI, 1992).

Árvore pioneira de rápido crescimento, o pauviola se adapta bem a terrenos úmidos e brejosos. Em razão disso, é indispensável em plantios mistos destinados à recomposição de áreas ciliares degradadas, como também tem seus frutos muito consumidos por pássaros e suas flores são objeto de visitas de abelhas (CARVALHO, 1994).

A Cedrela odorata da família Meliaceae, é popularmente conhecida como cedro-do-brejo ou cedro vermelho, e é uma árvore típica do continente americano, ocorrendo do México à Argentina. No Brasil, pode ser encontrado nos biomas da Mata Atlântica, da Amazônia e da Caatinga. Esta espécie pode atingir de 25 a 35 metros de altura, com tronco fissurado de 90 a 150 centímetros de diâmetro. Tratase de uma planta decídua, heliófita ou de luz difusa seletiva higrófita, característica das matas primárias e secundárias altas de terra firme. (LORENZI, 1992). Devido à sua madeira de alta qualidade e à consequente exploração excessiva, a espécie está hoje ameaçada de extinção (CARVALHO, 1994).

O objetivo deste estudo foi avaliar os efeitos da aplicação de subdoses de glyphosate na produção de mudas de Psidium cattleyanum, Citharexylum myrianthum e Cedrela odorata L. através da análise de seus parâmetros morfofisiológicos.

\section{MATERIAL E MÉTODOS}

$\mathrm{O}$ experimento foi realizado durante os meses de outubro de 2010 e janeiro de 2011, em condições de casa de vegetação climatizada, com temperatura média de $26^{\circ} \mathrm{C}$, sendo um para cada espécie estudada (Psidium cattleyanum, Citharexylum myrianthum e Cedrela odorata).

As mudas utilizadas para aplicação foram produzidas em sacos plásticos preenchidos com substrato comercial Plantimax, o qual é utilizado no viveiro comercial para produção de mudas de espécies nativas, e a aplicação do herbicida foi realizada 120 após a germinação das três espécies, quando estas estavam com as seguintes alturas médias: Psidium cattleyanum $10 \mathrm{~cm}$, Citharexylum myrianthum $5 \mathrm{~cm}$, e Cedrela odorata $13 \mathrm{~cm}$.

Foi realizada aplicação do herbicida glyphosate na formulação comercial Scout ${ }^{\circledR}$, nas seguintes doses: $0,7,5,15,30$ e 60 g e.a. ha ${ }^{-1}$. Foi utilizado um pulverizador costal, equipado com barra de aplicação contendo quatro pontas de pulverização tipo jato plano XR11002 VS, com um consumo de calda de $200 \mathrm{~L} \mathrm{ha}^{-1}$.

O experimento foi conduzido por 90 dias após aplicação dos tratamentos. Foram realizadas 
avaliações dos efeitos dos tratamentos químicos sobre as plantas aos 7, 14 e 21 dias após aplicação através de uma escala porcentual de notas, na qual zero consiste em ausência de injúria e cem em morte das plantas (SBCPD, 1995).

Ao final do período de 90 dias, foram realizadas avaliações da altura, diâmetro do caule, condutância estomática, medida com o porômetro (DECAGON Leaf Porometer - Model SC-1), como também massa seca de parte aérea, obtida em estufa de ventilação forçada de ar a $60 \pm 2{ }^{\circ} \mathrm{C}$ até atingir massa constante. A altura e o diâmetro também foram medidas no momento da aplicação para ter-se o ganho (incremento) destes parâmetros ao final do experimento.

O delineamento foi em delineamento inteiramente casualizado, com seis repetições. Os dados foram submetidos à análise de regressão polinomial, em arranjo fatorial (5 doses x 3 espécies), no qual foi selecionado o modelo significativo de maior ordem (R2) empregando-se a equação que melhor se ajustou aos dados.

\section{RESULTADOS E DISCUSSÃO}

Não foi obsevado efeito de fitointoxição do herbicida em nenhuma das três espécies estudadas. Observa-se, pelas curvas de regressão um aumento de todos os parâmetros avaliados de acordo com o aumento da dose do herbicida para o pau-viola e o
PEREIRA, M. R. R. et al.

araçá-amarelo, o que pode explicar o fato de nenhum tratamento nestas espécies, causar fitointoxicação às plantas.

A massa seca das plantas de pau-viola e araçá-amarelo apresentaram aumento aos 90 dias após aplicação das subdoses de glyphosate, atingindo valores máximos de 37,8\% (dose de 30g) e de $106,9 \%$ com a dose de $60 \mathrm{~g}$, para as respectivas espécies (Figura 1). Com a aplicação de $60 \mathrm{~g} \mathrm{ha}^{-1}$ nas plantas de pau-viola verifica-se queda dos resultados, em comparação à dose de $30 \mathrm{~g}$, mas ainda assim, maiores que os valores observados na testemunha.

Diferentemente das outras espécies estudadas, o cedrinho não respondeu satisfatoriamente às aplicações de subdoses de glyphosate. Todos os parâmetros avaliados diminuíram conforme se aumentou a dose, com redução de até $26,1 \%$ com a aplicação de $60 \mathrm{~g}$.

Estes resultados evidenciam que $\mathrm{o}$ glyphosate em doses reduzidas pode induzir a um maior desenvolvimento das plantas de pau-viola (Cyntharexyllum myrianthum) e araçá-amarelo (Psidium cattleyanum), podendo agir como um regulador de crescimento para estas espécies, sendo que com este aumento de massa seca a planta poderá apresentar maior área fotossintética o que possibilitará um crescimento mais rápido, tornando esta planta mais agressiva e resistente à matocompetição

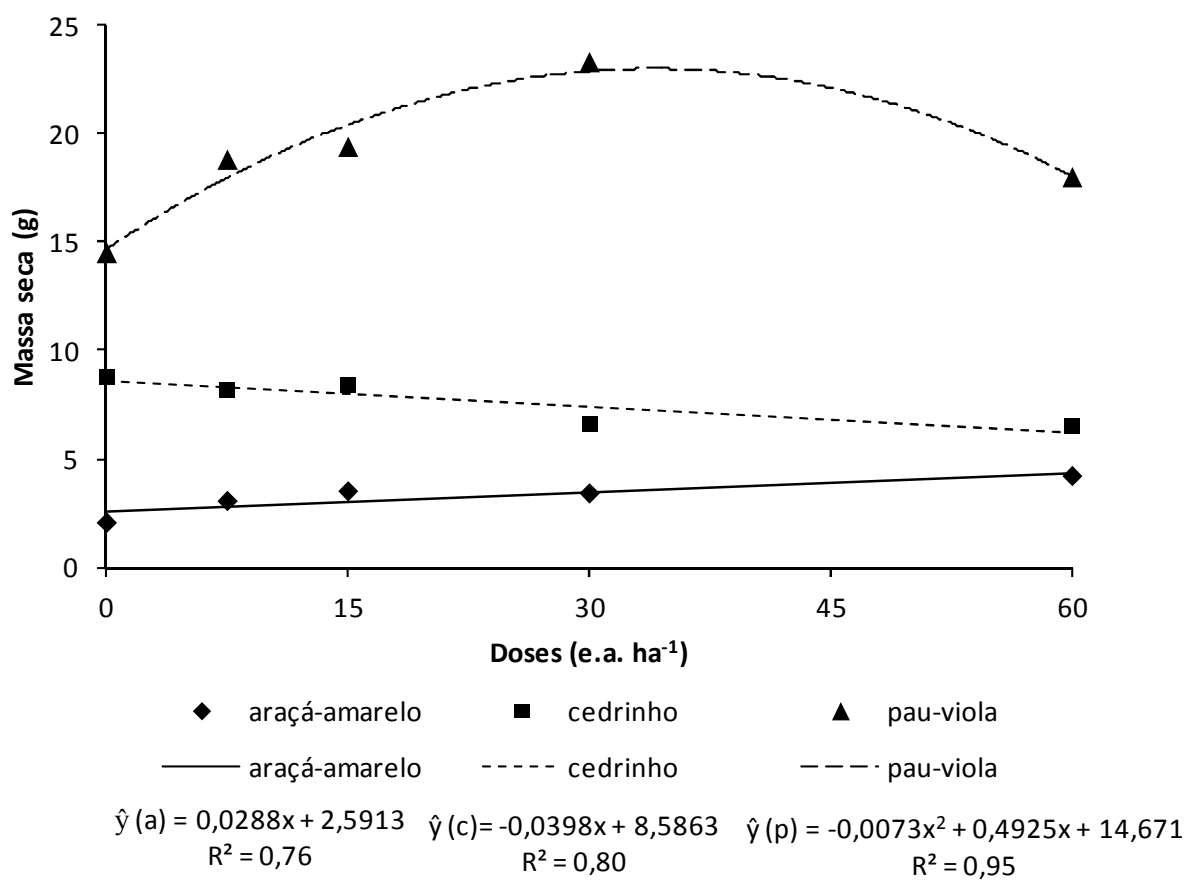

Figura 1. Massa seca de plantas de araçá-amarelo, cedrinho e pau-viola, submetidas à aplicação de diferentes subdoses de glyphosate. Botucatu/SP, 2010/2011. 
O diâmetro em plantas de pau-viola e araçáamarelo apresentaram acréscimos de acordo com o aumento da dose aplicada do herbicida. Os maiores valores foram observados nas plantas de pau-viola submetidas à dose de $30 \mathrm{~g} \mathrm{ha}^{-1}$, sendo o aumento de $51,6 \%$ e em plantas de araçá-amarelo foi verificado incremento em todos os tratamentos aplicados, sendo de até $68,6 \%$ com a dose de $60 \mathrm{~g} \mathrm{ha}^{-1} \mathrm{em}$ relação à testemunha. Já, no cedrinho, o incremento em diâmetro das plantas com a aplicação de $60 \mathrm{~g}$ apresentou reduções em média de $31,7 \%$ em relação à testemunha (Figura 2).

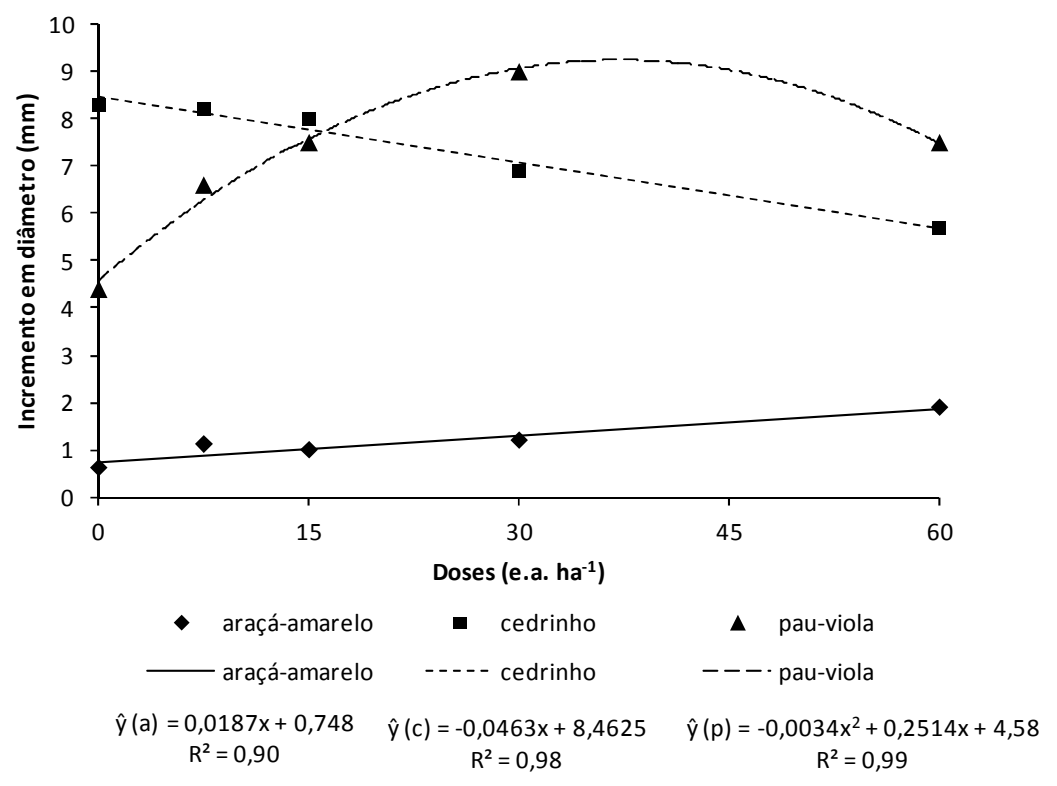

Figura 2. Incremento em diâmetro plantas de araçá-amarelo, cedrinho e pau-viola, submetidas à aplicação de diferentes subdoses de glyphosate. Botucatu/SP, 2010/2011.

Acompanhando os resultados já descritos, o incremento em altura também foi maior nas plantas de pau-vila e araçá-amarelo. Nas plantas de pauviola os melhores resultados foram verificados com a aplicação da dose de $30 \mathrm{~g}$, sendo $32 \%$ maior que a altura das plantas sem aplicação, e para o araçáamarelo a dose que proporcionou maior incremento foi a de $60 \mathrm{~g}$, como já observados nos outros parâmetros avaliados, sendo de $105,7 \%$, em relação à testemunha. $\mathrm{O}$ incremento em altura do cedrinho reduziu com o aumento da dose aplicada, atingindo redução de até $41,2 \%$, Esta espécie se mostrando-se assim sensível ao glyphosate, mesmo em subdosagens (Figura 3).

Resultados semelhantes foram encontrados por Tuffi et al. (2006), em um estudo com mudas de Eucalyptus urophylla (em média com $30 \mathrm{~cm}$ de altura) e aplicação de 43,2 $\mathrm{g} \mathrm{ha}^{-1}$ de glyphosate, com aumento em altura e diâmetro, em comparação com a testemunha. Corroborando estes resultados, Pereira et al. (2010), verificaram que a aplicação de $60 \mathrm{~g}$ de glhyphosate acarreta uma diminuição da resistência estomática e consequentemente aumento da transpiração gerando uma redução na temperatura das folhas, inferindo que o glyphosate nesta subdose, agiu como estimulante de crescimento.
Segundo Pereira et al. (2011) o herbicida glyphosate em subdoses acima de $80 \mathrm{~g} \mathrm{ha}^{-1}$ pode afetar negativamente o crescimento do eucalipto, diminuindo o ganho em altura e diâmetro, massa seca da parte aérea e área foliar, sendo observadas, com a aplicação de $40 \mathrm{~g}$, fitointoxicação inicial (7 DAA) de $40 \%$ e final (35 DAA) de $10 \%$, havendo uma recuperação das plantas com o tempo.

Comparando-se as três espécies, verifica-se maior tolerância do araçá-amarelo, pois a tendência das linhas é de aumento em todos os parâmetros avaliados, conforme há o aumento da subdose. Observa-se que o cedrinho foi a espécie mais sensível ao glyphosate, não sendo recomendada sua aplicação para estímulo de crescimento.

A sensibilidade ao herbicida glyphosate é variável com a espécie florestal estudada e da dose utilizada, podendo agir como um estimulante para o crescimento ou causador de injúrias e morte da planta.

Existem também espécies que se mostram tolerantes às subdoses de glyphosate, como a Hevea brasiliensis (seringueira), como constataram Farias et al., (2012). Com a aplicação de $6 \%$ da dose comercial recomendada $\left(3,0 \mathrm{~L} \mathrm{ha}^{-1}\right.$ do produto comercial), $75 \%$ das plantas apresentaram injúrias consideradas leves, com total recuperação aos 180 DAA, como verificado 
também com $24 \%$ da dose comercial. Não houve incremento em altura e diâmetro com nenhuma das aplicações, portanto, não se recomenda a aplicação de subdose de glyphosate para estímulo de crescimento, mas sim a aplicação para controle de plantas daninhas nesta cultura, já que concluiu-se que esta espécie apresenta tolerância à deriva.

Na Figura 4 estão apresentados os resultados das avaliações de condutância estomática, que pode ser entendida como mecanismo fisiológico que as plantas terrestres vasculares possuem para o controle da transpiração (JARVIS; MCNAUGHTON, 1986), através da regulação da abertura do estômato que pode ser influenciada diretamente por fatores ambientais como a luz, a umidade do ar, a concentração de gás carbônico, o potencial de água da folha e a temperatura (SCHULZE et al., 1987, TENHUNEN et al., 1987).

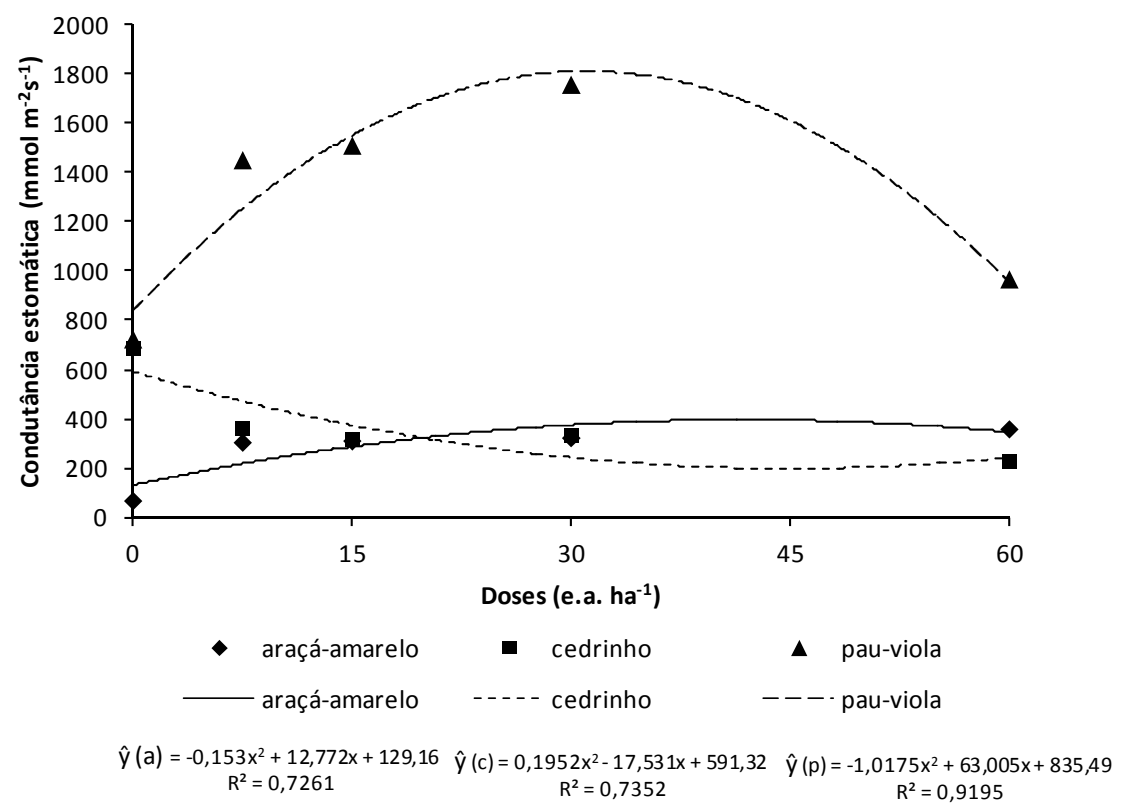

Figura 4. Condutância estomática de plantas de araçá-amarelo, cedrinho e pau-viola, submetidas à aplicação de diferentes subdoses de glyphosate. Botucatu/SP, 2010/2011.

Os dados observados possuem comportamento semelhante ao das outras avaliações, sendo as maiores condutâncias em plantas de pau-viola com a aplicação de $30 \mathrm{~g}$ e.a. de glyphosate, decrescendo com o amento da dose. Para as plantas de araçá-amarelo, o comportamento da condutância também é semelhante, aumentando proporcionalmente ao aumento da dose. Em contraste, nas plantas de cedrinho verifica-se uma diminuição da condutância com o aumento da dose. Estes resultados explicam o maior desenvolvimento daquelas espécies com a aplicação de glyphosate, pois, quanto maior a condutância estomática, maior a transpiração, portanto maior o crescimento.

De acordo com Pereira et al. (2010), em estudo com plantas de E. grandis em estádio inicial, a aplicação de $60 \mathrm{~g}$ do equivalente ácido de glyphosate acarreta uma redução na transpiração, aumento da resistência estomática e da temperatura foliar. Já, com a aplicação de $30 \mathrm{~g}$, tem-se uma diminuição da resistência estomática e consequente aumento da transpiração gerando uma redução na temperatura das folhas, o glyphosate nesta subdose, pode ter agido também como um estimulante de crescimento em plantas de eucalipto.

Nas avaliações de regressão, observa-se um comportamento parabólico das variáveis avaliadas em plantas de pau-viola, o que pode ser explicado pelo fenômeno denominado "Hormesis", que supõe que em doses muito baixas os herbicidas poderiam estar estimulando o crescimento das plantas. Este termo foi introduzido por Erlich em 1943, para descrever o fenômeno no qual substâncias que são tóxicas em doses elevadas podem ser benéficas em doses baixas (CALABRESE, 2005), como foi demonstrado por vários autores aqui citados.

Exemplos de "Hormesis" também ocorrem em culturas agrícolas como verificado por Duke et al. (2006), em estudo com vários herbicidas proporcionando o incrementos em altura, massa de matéria seca e teor de proteína, entre outros, em culturas como soja, trigo, milho e centeio, como também Tiburcio et al. (2012), que notaram que a ação do herbicida tembotrione em clones de eucalipto, em todas as doses avaliadas (3, 6 e $12 \%$ 
da dose recomendada), estimulou, em menor ou maior grau, o crescimento em altura.

\section{CONCLUSÕES}

As diferentes doses do herbicida não provocaram fitointoxicação em nenhuma das espécies testadas. Já, a dose de 30 e $60 \mathrm{~g}$ e.a. ha ${ }^{-1}$ proporcionou maiores incrementos em altura e diâmetro, bem como maiores massas secas em plantas de pau-viola e araçá-amarelo, respectivamente.

Todos os parâmetros avaliados do cedrinho reduziram com a aplicação do glyphosate, independente das doses.

\begin{abstract}
Recovery of degraded areas aims to provide the degraded environment favorable conditions for restructuring in an environment that is unable to regenerate itself and planting of tree seedlings is one of the effective ways to extend this process. However, native tree species have slow growth rate which increases the seedlings production time as well as decreases their competitiveness with weeds in areas of forests deployment. The aim of this study was to evaluate the effects of glyphosate reduced rates application on Psidium cattleyanum (yellow guava), Citharexylum myrianthum (pau-viola) and Cedrela odorata (cedro) seedlings development by analyzing its morphophysiological parameters. The experiment was carried out in greenhouse conditions and the experimental units consisted of one plant were conducted in $2.5 \mathrm{~L}$ plastic pots and arranged in a completely randomized design with six replications. Treatments consisted of glyphosate application at $0,7.5,15$, 30 and $60 \mathrm{~g} \mathrm{ha}^{-1}$ using Scout ${ }^{\circledR}$ commercial formulation. Treatments application on these species seedlings was realized 120 days after seeds germination. Visual evaluations of plants phytotoxicity were realized at 7, 14 and 21 days after treatments application and plants survival, stomatal conductance, height, stem diameter and dry mass of shoots were evaluated 90 days after treatments application. Different doses of glyphosate did not cause plants phytotoxicity. Already, 30 and $60 \mathrm{~g} \mathrm{ha}^{-1} \mathrm{of}$ glyphosate provided greater increases in height, stem diameter and dry mass of shoots for Citharexylum myrianthum and Psidium cattleyanum, respectively.
\end{abstract}

KEYWORDS: Psidium cattleyanum. Citharexylum myrianthum e Cedrela odorata. Herbicide.

\title{
REFERÊNCIAS
}

CALABRESE, E. J. Historical blunders: how toxicology got the dose-response relationship half right. Cellular and Molecular Biology, Noisy-le-grand, v. 51, n. 7, p. 643-654, 2005.

CARVALHO, P. E. R. Espécies florestais brasileiras. Recomendações Silviculturais, potencialidades e uso da madeira. Brasília, EMBRAPA-CNPF. 1994. 640p.

DUKE, S. O.; CEDERGREEN, N.; VELINI, E. D.; BELZ, R. G. Hormesis: Is it an important factor in herbicide use and allelopathy? Outlooks on Pest Management, Essex, February, v. 17, n. 1, p. 29-33, 2006.

FARIAS, C. C. M.; RONDON NETO, R. M.; YAMASHITA, O. M.; FARIAS, C. B. M. Efeitos de subdoses de glyphosate em plantas jovens de seringueira (Hevea brasiliensis Aubl.). Revista Brasileira de Herbicidas, Maringá, v. 11, n. 1, p. 119-125, 2012.

FERNANDES, L. A.; FURTINI NETO, A. E.; FONSECA, F. C.; VALE, F. R. crescimento inicial, níveis críticos de fósforo e frações fosfatadas em espécies florestais. Pesq. agropec. bras., Brasília, v. 35, n. 6, p. 1191-1198, 2000.

FERREIRA, R. A.; SANTOS, P. L.; ARAGÃO, A. G.; SANTOS, T. I. S.; SANTOS NETO, E. M.; E REZENDE, A. M. S. Semeadura direta com espécies florestais na implantação de mata ciliar no Baixo São Francisco em Sergipe. Scientia Forestalis, Piracicaba, v. 37, n. 81, p. 37-46, 2009.

GARRIDO, M. A. O. Caracteres silviculturais e conteúdo de nutrientes no folhedo de alguns povoamentos puros e mistos de espécies nativas. 1981. 105p. Dissertação ( Mestrado em Engenharia Florestal). Piracicaba: ESALQ. 1981. 
INSTITUTO BRASILEIRO DE FLORESTAS. Disponível em: http://www.ibflorestas.org.br/pt/lista-deespecies-nativas/411-araca-amarelo.html. Acesso em 02 de março de 2013.

JARVIS, P. G.; McNAUGHTON, K. G. Stomatal control of transpirations: scaling up from leaf to region. Advances Ecological Research, Londres, v. 15, p. 1-49, 1986. http://dx.doi.org/10.1016/S00652504(08)60119-1

LORENZI, H. Árvores brasileiras. Manual de Identificação e cultivo de plantas arbóreas nativas do Brasil. Nova Odessa. Ed. Plantarum. 1992. 352p.

PEREIRA, M. R. R.; RODRIGUES, A. C. P.; COSTA, N. V.; MARTINS, D.; KLAR, A. E.; SILVA, M. R. Deriva de glyphosate sobre características fisiológicas em plantas de eucalipto. Interciencia, Caracas, v. 35, n. 4, p. 279-283, 2010.

PEREIRA, M. R. R.; RODRIGUES, A. C. P.; CAMPOS, C. F.; MELHORANÇA FILHO, A. L.; MARTINS, D. Absorção de subdoses glyphosate aplicadas em diferentes locais de plantas de eucalipto. Revista Árvore, Viçosa, v. 35, n. 3, p. 589-594, 2011.

PITELLI, R. A.; MARCHI, S. R. Interferência das plantas invasoras nas áreas de reflorestamento. In: SEMINÁRIO TECNICO SOBRE PLANTAS DANINHAS E O USO DE HERBICIDAS EM REFLORESTAMENTO. 1991, Rio de Janeiro. Anais... Rio de Janeiro: SIF, 1991. p. 110-123.

REITZ, R.; KLEIN, R. M. Mirtáceas (Flora Ilustrada Catarinense). Itajaí, Herbário Barbosa Rodrigues. 1977, $158 \mathrm{p}$.

RIBEIRO C. A. A. S.; SOARES, V. P.; OLIVEIRA, A. M. S.; GLERIANI, J. M. O desafio da delimitação de áreas de preservação permanente. Revista Árvore, Viçosa, v. 29, n. 2, p. 203-212, 2005.

RODRIGUES, B. N.; ALMEIDA, F. S. Guia de herbicidas. Londrina: IAPAR, 2005. 591 p.

SCHULZE, E. D. et al. Stomatal responses to air humidity and to soil drought. In: ZEIGER, E.; FARQUHAR, G.; COWAN, I. (Ed.). Stomatal function. Stanford: Stanford University Press, 1987. p. 311-321.

SILVA, A. C.; FERREIRA, F. A.; FERREIRA, L. R. Manejo integrado de plantas daninhas em hortaliças. 2006. Disponível em: <http://www .aptaregional .sp.gov.br/ artigo .phpid_artigo=456>. Acesso em 31 de julho de 2012.

SOCIEDADE BRASILEIRA DA CIENCIA DAS PLANTAS DANINHAS. Procedimentos para instalação, avaliação e análise de experimentos com herbicidas. Londrina: SBCPD, 1995. 42p.

TENHUNEN, J. D.; PEARCY, R. W.; LARANCE, O. L. Diurnal variation in leaf conductance and gas exchange in natural environments. In: ZEIGER, E.; FARQUHAR, G.; COWAN, I., (Ed.). Stomatal function. Stanford: Stanford University Press, 1987. p. 323-351.

TIBURCIO, R. A. S.; FERREIRA, F. A.; PAES, F. A. S. V.; MELO, C. A. D.; MEDEIROS, W. N. Crescimento de mudas de clones de eucalipto submetidos à deriva simulada de diferentes herbicidas. Revista Árvore, Viçosa, v. 36, n. 1, p. 65-73, 2012.

TOLEDO, R. E. B.; DINARDO, W.; BEZUTTE, A. J.; ALVES, P. L. C. A.; PITELLI, R. A. Efeito da densidade de plantas de Brachiaria decumbens sobre o crescimento inicial de Eucalyptus grandis. Scientia Forestalis, Piracicaba, n. 60, p. 109-117, 2001.

TUFFI SANTOS, L. D. ; FERREIRA, F. A.; FERREIRA, L. R.; DUARTE, W. M. ; TIBURCIO, R. A. S. ; MACHADO, A. F. L. Intoxicação de espécies de eucalipto submetidas à deriva do glyphosate. Planta Daninha, Viçosa, v. 24, n. 2, p. 359-364, 2006. 